\title{
Epiplasmins and epiplasm in Paramecium: the building of a submembraneous
}

\section{cytoskeleton.}

Aubusson-Fleury Anne ${ }^{1}$, Bricheux Geneviève ${ }^{2}$, Damaj Raghida ${ }^{2}$, Lemullois Michel ${ }^{1,}$ Coffe Gérard $^{2}$, Donnadieu Florence ${ }^{2}$, Koll France ${ }^{1}$, Viguès Bernard ${ }^{2}$

Bouchard Philippe $^{2}$

1 : Dynamique cellulaire chez la Paramécie, CNRS, Centre de Génétique Moléculaire, UPR3404, F-91198 Gif-sur-Yvette, France ;

Université Paris-Sud, F-91405 Orsay, France

2 : Clermont Université, Université Blaise Pascal, Laboratoire "Microorganismes : Génome et Environnement", BP 10448, F-63000 CLERMONT-FERRAND

CNRS, UMR 6023, LMGE, F-63171 AUBIERE

\section{Address for correspondance:}

Anne Aubusson-Fleury:

CNRS, Centre de Génétique Moléculaire, Avenue de la Terrasse, F-91198 Gif-sur-Yvette, France

FAX : 003369823181

Mail : anne.aubusson@cgm.cnrs-gif.fr

Running title: Epiplasm and epiplasmins in Paramecium. 


\section{Summary}

In ciliates, basal bodies and associated appendages are bound to a submembrane cytoskeleton. In Paramecium, this cytoskeleton takes the form of a thin dense layer, the epiplasm, segmented into regular territories, the units where basal bodies are inserted. Epiplasmins, the main component of the epiplasm, constitute a large family of 51 proteins distributed in 5 phylogenetic groups, each characterized by a specific molecular design. By GFP-tagging, we analyzed their differential localisation and role in epiplasm building and demonstrated that: 1) The epiplasmins display a low turnover, in agreement with the maintenance of an epiplasm layer throughout the cell cycle; 2) Regionalisation of proteins from different groups allows us to define rim, core, ring and basal body epiplasmins in the interphase cell; 3) Their dynamics allows definition of early and late epiplasmins, detected early versus late in the duplication process of the units. Epiplasmins from each group exhibit a specific combination of properties. Core and rim epiplasmins are required to build a unit; ring and basal body epiplasmins seem more dispensable, suggesting that they are not required for basal body docking. We propose a model of epiplasm unit assembly highlighting its implication in structural heredity in agreement with epiplasmins evolutionary history.

Keywords: basal body docking, transition zone, ciliogenesis, cell morphogenesis, structural heredity, Ciliates 
Ciliated protists are highly differentiated cells that possess many cilia. Because they are able to duplicate their cell pattern during division, they constitute pertinent models to decipher the mechanisms of cell morphogenesis. All ciliates have developed a conspicuous superficial cytoskeleton, the architecture of which depends upon the taxa (Fleury et al., 1992). A prominent example of these subsurface cytoskeletons is a submembraneous layer called epiplasm (Fauré-Fremiet, 1962; Peck, 1977). Cell fractionation has shown that all superficial structures, such as the basal bodies that support the cilia, as well as their associated appendages, are bound to this surface cytoskeleton (Collins et al., 1980). Because it appears as a permanent structure, this superficial cytoskeleton may act at the cell level as a structural integrator for positioning and anchoring the newly assembled elements during cell division. One way to understand how the complex cell morphology is achieved is thus to decipher the organisation and the assembly of this superficial cytoskeleton.

The epiplasm appears as a biochemically complex structure, built up with several different families of proteins:

- the articulins, first defined in Euglena (Marrs and Bouck, 1992); articulins and articulins-like proteins were later found in ciliates (Pseudomicrothorax, Huttenlauch et al., 1998a; Euplotes, Kloetzel et al., 2003).

- the epiplasmins, main components of the epiplasm, and thus by definition specific for ciliates where the structure has been defined. The epiplasms of the two species Tetrahymena and Paramecium differ in the nature of their molecular composition. In Tetrahymena, three major components of the epiplasm were first identified biochemically (Williams et al., 1979), then localised (Williams et al., 1995), and finally, for one of them, characterized as a lamin motif bearing protein (EpiC, Bouchard et al., 2000) required for cell shaping (EPC1, Williams, 2004). In addition, 
quantitatively minor yet uncharacterized components have also been detected $(\mathrm{K}$ antigens, Williams et al., 1990). By contrast, the Paramecium epiplasm proteins, which have also been characterized biochemically (Coffe et al., 1996), localised (Nahon et al., 1993) and finally identified (Pomel et al, 2006; Damaj et al, 2009), have no counterparts in other organisms. We will consider these proteins as the epiplasmins sensu stricto.

Out of these three protein families, two, the articulins and the epiplasmins sensu stricto, are characterized by a central domain of repetitive hydrophobic residues flanked with two more divergent terminal domains (Huttenlauch et al., 1998a; Kloetzel et al., 2003; Pomel et al., 2006; Damaj et al., 2009). In most ciliates analyzed so far, both articulins and epiplasmins were detected in fractions of the superficial cytoskeleton (Huttenlauch et al., 1998b), but their relative contribution in building the surface cytoskeleton remained unknown. This paper provides the first detailed analysis of the localisation of several epiplasmins within the epiplasm layer in one species, Paramecium tetraurelia.

In this species, the epiplasm is segmented in small regular territories known as units, in the center of which basal bodies are inserted (Jeanmaire et al., 1993). A multigenic family of 51 proteins organized into 5 groups of phylogenetically related epiplasmins is thought to constitute the main components of the epiplasm (Pomel et al., 2006; Damaj et al., 2009). Proteins of each group are characterized by a combination of conserved motifs arranged in a symmetric (groups 1, 3 and 5), an asymmetric (group 2) or atypic (group 4) configuration (Damaj et al., 2009). If functional analyses have shown that symmetric, asymmetric and atypic epiplasmins are required for proper assembly of the epiplasm unit (Pomel et al., 2006; Damaj et al., 2009), the role of the epiplasmins of different groups in epiplasm building is not understood. Are all these proteins assembled in an isotropic layer to form the units or do they play differential roles in building unit sub-domains? 
In this study, we analyzed the localisation and the role of epiplasmins of different groups. The results presented here show that the epiplasmins have a very low turnover and display different localizations in the unit, allowing us to define rim, core, ring and basal body epiplasmins, as well as different timings of deposition, early and/or late, during unit assembly. According to these criteria, the epiplasmins of different phylogenetic groups and subgroups exhibit a specific combination of properties. The emergent model of unit assembly sheds light on the process of basal body anchoring at the cell surface, as well as on the scaffolding function of the epiplasm layer in cell shaping and structural inheritance.

\section{Results}

\section{Organisation and duplication of the epiplasm in interphase and dividing Paramecium.}

In Paramecium, the basal bodies and their associated cilia are patterned into antero-posterior curved rows which delimit a central ciliated invagination, the oral apparatus. A sub-surface cytoskeleton, the epiplasm, reinforces the cell surface. The localisation of the epiplasmins has been visualized with the antibodies I4B7 and CTS32, whose specificity has been established by blotting against various cytoskeletal fractions (Jeanmaire et al., 1993; Nahon et al., 1993). The CTS32 antibody, which recognizes a subset of epiplasmins (Nahon et al., 1993), decorates in the interphase cell all the epiplasm units (Fig. 1A), except their centers where basal bodies are inserted (Fig. 1a).

Paramecium is a highly asymmetric cell. The duplication of its pattern has been described in great detail (Iftode et al., 1989). At the local level, the duplication of the units begins with the assembly of one (Fig. 1b), and then eventually several basal bodies anterior to the parental one (Fig. 1c), associated with the elongation of the units along the antero-posterior axis, then their scission into two or more units. Finally the assembly of basal bodies restores the specific 
single or paired basal body pattern of the units. At the whole cell level, these events develop as several waves that invade the cell surface from the equator towards the two poles (Fig. 1B). These waves affect differentially different cell areas, so that the combination of these events leads to hyperduplication of some units in the equatorial region, to no duplication at the two cell poles thus called "invariant fields", or duplication of other units (Fig. 1C). Cell constriction progresses by sliding of equatorial cell territories towards the ventral side, so that the fission furrow will form the ventral sutures (Fig. 1 D, E and F).

\section{Localisation of GFP-epiplasmins in interphase cells}

In order to localize the epiplasmins from the different groups in the interphase cell, we transformed Paramecium cells by microinjection in the macronucleus of plasmids encoding for GFP-epiplasmins of different phylogenetic groups (see Damaj et al., Fig.1 for the phylogeny). When possible, the most expressed representatives of each group were chosen (See Fig. 2 and Supplementary table 1). The cells were cloned immediately after the microinjection. Within a clone, all cells displayed the same fluorescence level and pattern. Several clones with various levels of fluorescence intensity, which correspond to various levels of over-expression, were analyzed for each epiplasmin. Strong over-expression of epiplasmins of families 1, 2, 3b and 5 was damaging for the cells while that of family $3 \mathrm{a}$ and 4 was not; abnormal cells of such over-expressing clones were smaller and often stopped dividing within five divisions. Clones of cells unaffected by the expression of the tagged protein were chosen to study the protein localisation.

Two out of the three analyzed atypic GFP-epiplasmins of the group 4 (At4a/Epi11 and At4a/Epi43) were detected around the units on living cells; on double labelled cells, the GFP signal exactly encircled the CTS32 labelling (Fig. 3A). The third atypic epiplasmin 
(At4b/Epi40) gave a strong fluorescent cytoplasmic background with no specific signal at the cell surface.

The two asymmetric GFP-epiplasmins of the group 2 (As2a/Ep20 and As2b/Ep38) and the symmetric of the group 1 (S1a/Ep41) displayed a pattern similar to that described with the CTS32 antibody: they localized on the whole surface of the unit both on living cells and after double labelling (Fig. 3B and C). No data are available for S1b epiplasmins.

The same localisation on the whole surface of the unit was also observed for the symmetric GFP-epiplasmins of the group 3 (S3b/Ep46 and S3a/Epi30, Fig. 3F). A clear localisation at the centre of the unit was also detected with the symmetric GFP-epiplasmins of group 3a; this central labelling appears as a ring around the basal body (Fig. 3D and 3F).

While expression of the tagged gene resulted in a fluorescent cytoplasmic background for the 1-4 epiplasmin families, many clusters of GFP material, corresponding to over-expressed protein, were detected at all stages of the cell cycle in cells expressing the small symmetric epiplasmin of the group 5 (S5a/Epi51; 3E); this result suggests that this GFP-epiplasmin agglomerate. A GFP signal was detected at the centre of the unit as two or three spots (Fig. 3E). Double labelling showed that one or two of these spots co-localised with the basal bodies, while the additional spot localized to the anterior right of the basal body (Fig. 3G). No labelling at all was observed for the GFP-epiplasmin S5b/Ep48.

These results show that, in the interphase cell, different localisations are observed for different epiplasmins within each unit: peripheral, uniform and/or central. It is striking that some GFPepiplasmins also localized in the macronucleus, as observed in all clones for S3a/Epi30 (Fig. 3D) and in strongly over-expressing clones for As2b/Epi38 and S3b/Epi46 (not shown). The GFP localisation was analysed at the ultrastructural level by immunogold labelling both by pre- and post embedding. The results confirm the light-microscopical observation (Fig. 4; Table 1). A significant labelling was observed on the epiplasm layer while basal bodies were 
only weakly labelled on cells expressing GFP- asymmetric epiplasmins (As2a/Epi20, As2b/Epi38); the same localisation on the epiplasm layer was observed for the symmetric $3 \mathrm{a}$ epiplasmins, but with a dense labelling at the ring around the basal bodies (S3a/Epi30). The S5a/Ep51 was detected around and inside the basal bodies; in addition, labelling was detected around the parasomal sac (Fig. 4), an invagination of the external membrane through the epiplasm where endocytosis is supposed to take place (Kurz and Tiedtke, 1993); this labelling corresponds to the additional spot observed by immunofluorescence.

Differential localisations of GFP-epiplasmins were thus observed in interphase cells. Atypic epiplasmin 4 clearly localises at the unit periphery and for this reason, will be called rim epiplasmins. Asymmetric 2, symmetric 1 and 3 epiplasmins were detected in the whole unit; they constitute the core epiplasmins. A clear localisation around the basal bodies (ring epiplasmins) and at the basal body (basal body epiplasmins) is detected for the symmetric $3 \mathrm{a}$ and 5a epiplasmins.

\section{Localisation of GFP-epiplasmin during cell division.}

In order to understand how the different epiplasmins interplay to build the epiplasm unit, we analyzed the behaviour of the different epiplasmins from the beginning of the elongation of the units until the end of the process, both at the whole cell level and at the local level, using as a reference the CTS32 and the anti-glutamylated tubulin ID5 antibodies to label the epiplasm and the basal bodies respectively.

At the very beginning of elongation of the equatorial units, the future fission line is clearly detected within the epiplasm (Fig.1B); this line most probably corresponds to the thinning down of the layer. The first changes in GFP-epiplasmin labelling were observed at that stage. In this equatorial region, the GFP-labelling of the core epiplasmins is less bright (As2a/Epi20, S1a/Epi41 and S3a/Epi30) and/or disappears (As2b/Epi38 and S3b/Epi46) (Fig. 5A and B and 
Sup mat 1A). This observation suggests that all the epiplasmins do not accumulate at the same time during the unit elongation: the deposition of S1a, As2a and S3a epiplasmin precedes that of the As2b and S3b ones. We will call them respectively early and late epiplasmins. The GFP-epiplasmin S3a/Epi30 located at the epiplasmic ring around the basal body remains associated with the parental basal body as the unit elongates, but is fully detected around the new basal body only after unit individualization (Fig. 5C and Sup mat 1B), a long time after the docking of the new basal body at the cell surface. This result suggests that this ring epiplasmin is not required for basal body anchoring at the cell surface.

The question of the structural integrity of the complex basal body/epiplasm ring can be addressed thanks to the behaviour of the anterior invariant field. In this field, two basal bodies are paired within each unit. It is known that during division, as described previously during conjugation (Romero and Torres, 1993), the anterior basal body of each pair disappears and a new one is reassembled shortly after at the same place (see Aubusson-Fleury et al. 2012). We thus examined the permanence of the epiplasmic ring during this replacement. In dividing cells expressing the GFP S3a/Epi30, the two rings remain at the cell surface when the anterior basal body disappears (Sup mat 1C). This observation shows that the permanence of the epiplasm ring within the epiplasm layer does not depend upon the presence of the basal body. A delay between basal body assembly and GFP-S5a/Epi51 detection was also observed (Fig. 5E). This result suggests that this epiplasmin is not involved in basal body assembly and/or anchoring.

At the whole cell level, the GFP-labelling of the rim epiplasmins is also modified. The At4b/Epi40 epiplasmins, which were not detected in the interphase cell, displayed the same pattern as other representatives of the At4 subgroup (Sup mat 2A). At the beginning of cell division, the labelling of the At4 (At4a/Epi11; At4a/Epi43) lightens in the equatorial region (Fig. 5F); observation at high magnification shows that thin GFP-lines appear within the 
equatorial units. This process corresponds to the beginning of the scission of the units leading to their duplication (Sup mat 2C). Accumulation of GFP-At4 epiplasmin at the fission line is clearly detected (Sup mat 2 B and C).

All these data show that epiplasmins display specific behaviours during the complex process of building an epiplasm unit. The core epiplasmins S1a, As2a and S3a are early epiplasmins, added continuously during unit elongation; core As $2 \mathrm{~b}$ and $\mathrm{S} 3 \mathrm{~b}$ accumulate later, after the scission of the units. The epiplasmins which constitute the epiplasmic ring and/or located at the basal body, S3a/Epi30 and S5a/Epi51, remain associated with the parental basal body and are detected in association with new basal bodies after the full assembly of the unit. Finally, At4a epiplasmins remain around the unit during the whole process of unit duplication and separate the unit into two parts soon after basal body assembly; by contrast, At $4 \mathrm{~b} /$ Epi40 is detected only during the cell division.

\section{Dynamic of GFP-epiplasmin disappearance during unit morphogenesis.}

Because cells stop expressing microinjected transgenes after autogamy (see material and methods), it is possible to observe the turn-over of the proteins by following the disappearance of the GFP tag in post-autogamous cells. The behaviour of representatives of core and ring GFP-tagged epiplasmins was followed during the two first divisions after autogamy.

During division, invariant units asymmetrically distribute between the two daughter cells: the anterior field remains in the anterior cell and the posterior one in the posterior cell. It is thus possible to trace the cell and units lineage during at least the first two divisions after autogamy.

After autogamy, the GFP core epiplasmins of the parental invariant fields are retained in the cell progeny (S1a/Epi41 (Fig.5A), S3b/Epi46 and As2a/Epi20 (not shown)). The turnover of 
these GFP-epiplasmins in non proliferative units is thus very low. By contrast, these GFP epiplasmins became asymmetrically distributed between the anterior and the posterior units as they divide (S1a/Epi41 and S3b/Epi46 (Fig. 6), As2a/Epi20 (not shown)): new anterior units are not labelled at all, while GFP epiplasmin are detected only the posterior part of the posterior ones. This observation demonstrates that the growth of the epiplasm layer during unit elongation is an antero-posterior asymmetric process.

The ring GFP-epiplasmins are detected in association with the parental basal bodies after the first post-autogamous divisions (S3a/Epi30, Fig. 6B) and even later (not shown). This observation demonstrates that the ring epiplasmins have a very low turnover. Similarly, basal body epiplasmins GFP-S5a/Epi51 are also retained in the parental basal bodies (not shown). Unexpectedly, in this context of cessation of GFP expression, the GFP-S3b/Epi46, which was classified as a core epiplasmin in the interphase and dividing cell, appears also clearly localised in the ring (Fig. 6C), like its sister-group epiplasmin S3a/Epi30. The fact that it was not observed there in stably GFP-expressing cells probably results from the difficulty to detect the ring in a strongly fluorescent unit. Accordingly, careful examination of the GFPS3b/Epi46 dividing cells shows that the ring can be faintly detected during division of GFP expressing clones (not shown).

Finally, in the anterior invariant field of anterior division products of post-autogamous dividers, where the anterior basal body has been replaced in a context of cessation of GFP expression, the GFP S3a/Epi30, and GFP S3b/Epi46 were detected only in the ring associated with the posterior basal body. In GFP S3b/Epi46 post-autogamous cells, a hole was detected in the core GFP epiplasmin of the unit in place of the anterior basal body (Fig. 6C). This observation demonstrates that GFP S3b/Epi46 ring epiplasmin is replaced at the time of basal body replacement while the core one has been retained: the two structures, core epiplasm of 
the unit layer and epiplasmic basal body ring, both display a specific turnover of their constitutive GFP epiplasmins during the same period of time.

\section{Effect of epiplasmin depletion and overexpression.}

In order to look for the role of different epiplasmins in the process of unit building, we performed epiplasmin depletion by feeding. In addition, data were obtained from abnormal phenotypes observed in cells expressing GFP-tagged epiplasmins. These abnormalities were probably related to over-expression because their occurrence correlated with the fluorescence intensity.

As shown in a previous paper (Damaj et al., 2009), depletion of core epiplasmins of the families 1 (S1a/Epi41) and 2 (As2a/Epi2) induced aborted division resulting in characteristic phenotypes in 24 to 48 hours. At the local level, each of these two depletions impaired the unit morphology in a specific way: many small abnormal units were observed after As2a/Epi2 depletion, while, after S1a/Epi41 depletion, agglomerates of CTS32 positive material were detected between the antero-posterior rows of units. Additional results obtained in this study with genes encoding other epiplasmins of these groups (see Fig. 2 and Supplementary table 1 for a summary) gave the same results. Accordingly, strong over-expressions of these GFP core epiplasmins also impaired cell morphology and morphogenesis: in clones exhibiting a strong fluorescence, cells with abnormal shapes and cortical units were observed. Such clones stopped dividing after 3-4 divisions (As2a/Epi20: 23/30 clones; As2b/Epi38: 15/23 clones; S1a/Epi41: 10/16 clones).

Among three epiplasmin depletions of the S3 family tested, only one, S3b/Epi46, gave a faint non reproducible phenotype at the whole cell level similar to phenotypes obtained after depletion of symmetric 1 epiplasmin; no clear phenotype was observed at the unit level. This result suggests that ring epiplasmins may be dispensable for unit building and basal body 
anchoring. Accordingly, strong overexpression of GFP S3b/Epi46 (4/9 clones), but not of GFP S3a/Epi30 (0/28 clones), was damaging for the cells which stopped dividing after two or three divisions.

In the S5 family, the depletion of epiplasmins of each family, S5/Epi48 and S5/Epi51, as well as double depletion did not yield any phenotype at the light-microscopic level. At the ultrastructural level, abnormalities in the morphology of the parasomal sacs and of basal body transition zone were observed (Fig. 7): the epiplasm ring was not detectable, but the basal bodies were correctly anchored. By contrast, over-expression of the GFP S5/Epi51 strongly impaired cell growth and morphology: abnormal small cells were observed and the cells stopped dividing after a few divisions (22/26 clones).

Finally, depletion of At4a/Epi11 yielded a faint phenotype at the cell level: some cells moved slowly as compared to the control. In these cells, the immunofluorescence with CTS32 showed partially fused units indicating that these units have not completely separated during the division. By contrast, no phenotype was observed after depletion of At4a/Epi43 and At4b/Epi40 (At4a/Epi11: 13 clones; At4a/Epi43: 9 clones; At4b/Epi40: 7 clones analysed; not shown).

Altogether, these results highlight the different roles of the different epiplasmins: both symmetric and asymmetric core epiplasmins are necessary to build a unit. Rim epiplasmins are required for correct unit scission. Ring and basal body epiplasmins do not seem to be absolutely required for basal body anchoring, at least in standard conditions of growth. By contrast, overexpression of S5a/Epi51 tagged protein strongly interferes with cell morphology, showing that an altered protein may be more damaging for the cell than its depletion.

\section{Discussion}


The phylogeny of the epiplasmins defined 5 groups, each subdivided into two sub-groups, a and b (Damaj et al., 2009). The five groups of genes encode five sets of epiplasmins, each characterized by a specific protein design: large (group1), intermediate (group 3) and small (group 5) symmetric epiplasmins, asymmetric ones (group 2) and atypic ones (group 4). Each group is subdivided into two subgroups of high and low expression level (Damaj et al., 2009). In order to understand the role of this multiplicity of proteins in building the epiplasm, we localized representatives of each group by GFP tagging in the interphase cell, followed their behaviour during cell division, and analysed the consequence of their depletion and overexpression on epiplasm assembly. The results show that epiplasmins of each subgroup have a specific role. We will summarize these properties, and then propose a model of unit building, and finally discuss what these results bring to our knowledge of basal body anchorage and cellular morphogenesis.

\section{Paramecium epiplasmins of different groups exhibit non redundant properties.}

In Paramecium, the epiplasm is segmented in units, in the center of which basal bodies are inserted (Allen, 1971; Nahon et al., 1993). The localisation of GFP-epiplasmins in the interphase cell allows us to reveal four different localisations allowing us to define several epiplasmin types: (i) the rim epiplasmins, located at the unit periphery; (ii) the core epiplasmins, located over the whole unit except at its center where basal body is located; (iii) the ring epiplasmins located around the basal body and (iv) the basal body epiplasmins located at the basal body. During cell division, new epiplasm units are built up by elongation and then scission of the parental unit after docking at the cell surface of newly assembled basal bodies. The behaviour of the GFP epiplasmins during division allows defining early versus late epiplasmins according to the time of detection during the elongation of the unit. 
According to these criteria, localisation and behaviour, the epiplasmins of different groups display a specific set of properties (Fig. 8 and Table 2).

To what extent are these results also true for other members of the groups? Firstly, epiplasmins of one group all display the same specific molecular design, and may thus have similar functions. Secondly, the epiplasmins of two sister subgroups have the same localisation, thus suggesting that there is a correlation between the localisation and the phylogenetic affiliation to one group. Finally, depletion of epiplasmins within a group results in identical phenotypes specific for the group, thus suggesting that epiplasmins of one group have the same function. Taken together, these observations suggest that the results obtained here for one or two representatives of each subgroup may be extended to the whole group.

\section{Epiplasm unit assembly and structural heredity.}

The epiplasm layer is a permanent structure thought to ensure cell shaping and to act as a scaffold for anchoring many cytoskeletal elements, such as basal bodies and associated appendages (Peck, 1977; Williams et al., 1979; Collins et al., 1980). Cell shaping during division correlates with epiplasm unit assembly; depletion of epiplasmin proteins have shown that indeed, unit malformations correlate with abnormal cell morphology (Damaj et al., 2009). In this study, we show that, in the interphase cell, there is no turnover of GFP-epiplasmins. This result provides for the first time a strong argument in favour of the permanence of the epiplasm. In addition, the GFP-turn over observed during unit reproduction in GFPexpressing cells and/or after cessation of GFP expression allows us to propose a model for unit replication during cell division as following.

During cell division, the elongation of the parental unit correlates spatially and temporally with basal body assembly (Iftode et al., 1989): only units where basal body assembly has taken place elongate. For this reason, it has been suggested that the basal body could be the 
morphogenetic center of the unit (Iftode et al., 1989). Accordingly, detection of transversal rim epiplasmins close and posterior to the anterior new basal body marks the beginning of new unit individualisation.

Phosphorylation of the cytoskeleton correlates with its dynamics (Omary et al., 2006; Keryer et al., 1987, Sperling et al. 1991). As already discussed elsewhere (Damaj et al., 2009), since elongation is impaired by the serine-threonine-kinase inhibitor 6-DMAP (Kacszanowska et al., 1996), elongation of the units could be related to the phosphorylation status of the epiplasmins, which have a conserved potential serine-threonine-kinase site. We show here that the unit elongation is an antero-posterior asymmetric process: there is no turnover of epiplasmins in the posterior part of the unit, where the parental basal body is inserted, as well as no turn over of ring epiplasmins. By contrast, the anterior part of the unit, where new basal bodies anchor, is completely remodelled. This spatial asymmetry in epiplasmin turnover, which generates a scaffold for parental structures as new ones assemble, provides a basis for structural heredity during unit duplication.

\section{Role of the epiplasm in basal body docking and orientation}

The symmetric 3 and 5 epiplasmins are located at the distal part of the basal body, at the terminal plate of the transition zone and the epiplasm ring respectively. These ring and basal body epiplasmins are detected in association with new basal bodies a lag time after their assembly when epiplasm units have been fully individualized. Whether or not this observation reflects a limitation in the GFP-detection, it demonstrates that a fully assembled ring is not required for basal body anchoring to the cell surface. This result strongly suggests that basal body anchoring is a two-step process. In a first step, the basal body is linked to the cell surface; this event has been shown to require evolutionary conserved centrosomal proteins (Aubusson-Fleury et al., 2012). In a second step, the basal bodies could be locked on the 
subsurface cytoskeleton by additional links, like epiplasm rings; this event would result in fixing the definitive rotational orientation of the basal bodies at the end of cortical morphogenesis.

This result sheds new light on the issue of basal body/ciliary rotational orientation. In Paramecium units, the orientation of the newly assembled basal body is driven by that of the parental one, a long known phenomenon described as structural inheritance (Beisson and Sonneborn, 1965). Ultrastructural data have given strong arguments for a cytoskeletal basis for this phenomenon (Iftode and Fleury-Aubusson, 2003). Results presented here in Paramecium provide a first example of multistep cytoskeletal interactions between the nascent basal body and the subsurface cytoskeleton. If the hypothesis that the epiplasm ring plays a role in basal body locking is true, basal bodies whose relative orientation with respect to the cell polarity would be subject to change will lack this structure. Observation of basal bodies of the anarchic field in Paramecium interphase cells suggests that it is the case: these basal bodies, which will be reoriented during the next division to initiate the assembly of the new oral apparatus (Iftode et al., 1997) indeed lack the epiplasm ring (not shown). In multi-ciliated epithelia, the cell polarity and final orientation of the cilia within one cell are driven by successive mechanisms (Mitchell et al., 2007; Vladar and Axelrod, 2012; Vladar et al., 2012; Werner and Mitchell, 2012): while the cell polarity in reference to the tissue is given by asymmetric localisation of proteins of the PCP pathway, the refinement of basal body rotational orientation is driven by microtubules after their docking at the cell surface. But up to now, the mechanisms of locking up this final orientation only began to be questioned (Vladar et al., 2012). Results obtained in this study suggest that such specific mechanisms of basal body locking indeed exist and could be relayed by the superficial cytoskeleton. 


\section{Subsurface cytoskeleton and evolutionary diversification.}

All ciliates posses a submembrane cytoskeleton; depending upon the taxa, this cytoskeleton is built up according to different cytoskeletal strategies (Fleury et al., 1992), indicating that the cytoskeletal organization correlates with the phylogeny. Similarly, depending upon the taxa, the epiplasm layer occurs either as a continuous structure, where local differentiations are associated with the basal bodies, as for example in Tetrahymena (Williams et al., 1987; Williams, et al., 1995), or as a structure segmented in units where basal bodies are inserted as in Paramecium (Dippell, 1968). In both cases, a local differentiation, the dense collar (Allen, 1969) or pellicular ring in Tetrahymena (Allen, 1969; Collins et al., 1980) or the epiplasmic ring in Paramecium (Iftode et al.1996) encircles the basal bodies. Results obtained here in Paramecium show that this epiplasm ring provides a firm anchorage for the basal body while the epiplasm unit is remodelled, as for example during cell division. The emerging model is thus that, in both species, the cell is built up with basal bodies stably inserted by epiplasm rings within a dynamic layer.

Molecular data suggest that homologs for epiplasmins exist in Tetrahymena: homologs of asymmetric 2, symmetric 1, 3 and 5 have been identified in the Tetrahymena genome (EpiT1, EpiT2, EPiT3 and EpiT5, Damaj et al., 2009). Unfortunately, the localisation of these epiplasmins is not known in the Tetrahymena superficial cytoskeleton. The three main components of the Tetrahymena epiplasm layer are lamin-motif-bearing proteins (Bouchard et al., 2001). One hypothesis is that EpiT1 and EpiT2 would locate in basal body domains, as observed for As2 and S1 in Paramecium units, while EpiT3 would locate in the pellicular ring. If this is true, the EpiT1, EpiT2 and EpiT3 proteins could correspond to the yet unidentified K antigens (Williams et al, 1990). By contrast, atypic rim At4 epiplasmins, which define the limits of each unit, are not found in the genome of Tetrahymena (Damaj et al., 
2009). This correlation suggests that a function for these rim epiplasmins had emerged after the Paramecium/Tetrahymena divergence, or have been lost in the Tetrahymena lineage. It is striking that the segmentation of the epiplasm into units is common to all species of the Peniculina, the monophyletic subclass to which the Paramecium family belongs (StrüderKype et al., 2000). Highly asymmetrical cell morphologies are found in this taxonomic group. One hypothesis is that the segmentation of the layer into units allows more possibilities for cell surface deformation than a continuous layer would. Taken together, these results suggest that, through its composition, organization and assembly mechanisms, the subsurface cytoskeleton could have been one major support for morphological diversification in the course of ciliate evolution

To what extent does genome complexity correlate with morphological diversification? The epiplasmin phylogeny suggests that the large number of epiplasmin genes correlates with the several whole genome duplications (WGD) which have occurred during Paramecium history. The ortholog groups deduced from this history strongly suggest that two copies of epiplasm genes were already present in each of the five groups at the time of old WGD, which corresponds to the Tetrahymena/Paramecium divergence (Aury et al., 2006; see Paramecium DB). Because epiplasm units/domains are found in the two genera, the simplest hypothesis is that epiplasm units were already present at that evolutionary stage and the origin of such structures have thus to be explored by the comparison with genera of other subclasses. Two WGD have occurred since the Paramecium/Tetrahymena divergence, (Aury et al., 2006). Combination of molecular and morphological analyses suggests that the two Paramecium morphotypes, the aurelia-like and the bursaria-like, are phylogenetically distinct (Przybos et al., 2012). Bursaria-like species are shorter and more densely ciliated than aurelia-like ones; accordingly, epiplasm units of the Paramecium bursaria-like species ( $P$. calkinsi and $P$. bursaria) are very much smaller than those of the "aurelia group" (P. multimicronucleatum, 
P. caudatum and P.aurelia, unpublished observations). It is tempting to hypothesize that the intermediate WGD, which is known to have occurred between the Paramecium/Tetrahymena divergence and the emergence of the complex of P.aurelia sibling species, correlates with the extension of the units. Genome sequencing in progress from other Paramecium species will help to understand more about this yet poorly unexplored relation between genome complexity and morphological diversification.

\section{Material and Methods}

Strains and culture conditions. Stock d4-2 of Paramecium tetraurelia, was used in RNAi experiments and the mutant nd7-1 (Skouri and Cohen, 1997) which carries a recessive monogenic mutation preventing trichocyst discharge, was used for transformation. Cells were grown at $27^{\circ} \mathrm{C}$ in a wheat grass infusion, BHB (L'arbre de vie, Luçay Le Male, France), bacterised with Klebsiella pneumoniae and supplemented with $0.8 \mu \mathrm{g} / \mathrm{ml} \beta$-sitosterol according to standard procedures (Sonneborn, 1970).

Antibodies. The following antibodies were used: the monoclonal anti-glutamylated tubulin ID5 (Wehland and Weber, 1987) diluted 1:500 to label basal bodies; the monoclonal CTS32 diluted 1/10 directed against epiplasmins (Nahon et al., 1993) to decorate the epiplasm, and the polyclonal anti-GFP antibody (Interchim, Montluçon, France) diluted 1/1000 to amplify the GFP signal. Appropriate secondary (mouse or rabbit) antibodies from Jackson ImmunoResearch labs (West Grove, PA) Alexa 488 or Alexa 568 were used at a dilution of $1: 500$.

Gene cloning. For expression of the GFP-tagged proteins, the entire genes coding for epiplasmins of different subgroups (Supplementary table 1) were amplified from genomic DNA by PCR, using primers (5'-GCGGCGACTAGTATGxxxx-3') for the N-term side and (5'-GCGGCGCTCGAGxxxx-3') for the C-term. The PCR fragments were then digested with 
SpeI and XhoI and ligated in the vector pPXV-GFP (Hauser et al, 2000) digested with the same enzymes. After cloning, the genes were entirely sequenced to ensure that no error was introduced during the amplification. For silencing, the entire genes were cloned into the XhoI and HindIII site of the L4440 vector. This vector allows the synthesis of double-stranded RNA corresponding to the cloned gene from two T7 promoters. The off-target effects of these sequences were analyzed (Supplementary table 2).

Paramecium transformation. nd7-1 mutant cells were transformed by micro-injection into their macronucleus of filtered and concentrated plasmid DNA containing a mixture of the plasmids of interest $(5 \mu \mathrm{g} / \mu \mathrm{l})$ digested by Sfi1 and of plasmid DNA directing the expression of the ND7 wild type gene (Skouri and Cohen, 1997). Microinjection was made under an inverted Nikon phasecontrast microscope, using a Narishige micromanipulation device and an Eppendorf air pressure microinjector.

\section{Study of transformed clones}

The cells were cloned immediately after micro-injection. The clones were first screened for their ability to discharge their trichocysts and if so, further analyzed. The localisation of the GFP protein was observed by epifluorescence first on living cells, then on fixed and extracted cells and/or cells labelled for immunofluorescence observations.

In order to look at the GFP epiplasmin turnover, microinjected cells were grown for 20-25 divisions and then kept at the plateau phase until they entered autogamy. During this uniparental sexual process, the cell replaces its macronucleus, where GFP-tagged genes were mincroinjected, by a new wild type one which forms from a copy of the micronucleus and thus looses the GFP-tagged microinjected sequence. Cells were then kept at $18^{\circ} \mathrm{C}$ for one week, the time necessary for the complete degradation of old macronuclear fragments. After the disappearance of all old macronuclear fragments, the ex-autogamous cells, which stopped producing the GFP tagged protein, were grown at room temperature and processed for 
immunofluorescence during or after the first and then the second division to follow the disappearance of the GFP tagged version of the proteins.

Gene silencing. Gene silencing was performed by the feeding method as previously described (Galvani and Sperling, 2002). Stationary wild-type cells were fed with the appropriate doublestranded-RNA-expressing HT115 bacteria and transferred daily into fresh feeding medium as needed. Control cells were fed with bacteria transformed by the L4440 plasmid and the L4440 plasmid carrying the complete coding region of the $N D 7$ gene.

Phenotypic effects were analyzed first on living cells, and then by immunofluorescence on cells labelled with the CTS32 and/or the ID5 antibodies, and/or by electron microscopy. Immunofluorescence. For living observations, the cells were embedded in 2\% methyl cellulose (3000-5000 viscosity) Dryl solution, and observed by epifluorescence. GFP was also analysed on cells fixed (2\% paraformadehyde for $10 \mathrm{~min}$, then rinsed in PBS supplemented with BSA and $2 \mu \mathrm{g} / \mathrm{ml}$ Hoechst 33258 for nuclear staining). Alternatively, the cells were also permeabilized by Triton X100 in PHEM buffer before fixation. Immuno-staining of cells was carried out as previously described (Aubusson-Fleury et al., 2012). Cells were observed under a Zeiss Axiophot fluorescence microscope equipped with a Spot Insight SE camera. Alternatively, they were observed with a Confocal Nikon eclipse TE 2000-U microscope equipped with Argon and Helium-Neon lasers using the EZ-C1 3.30 software for acquisitions. Unless specified, images are projections of optical sections acquired at the level of one cell side. Projections were obtained using ImageJ (NIH) and images were annotated with Photoshop CS2 (Adobe).

Electron microscopy: For ultrastructural observations, the depleted and control cells were processed as described previously (Aubusson-Fleury et al., 2012). Both pre-embedding and postembedding protocols were used. For pre-embedding immunolocalization, the immunostaining process was carried out as described for immunofluorescence using a gold-coupled instead of fluorochrome-coupled secondary antibody. Then cells were rinsed, fixed and embedded as 
previously described. For post-embedding immunolocalization, cells were fixed in 3\% paraformaldehyde, $0.15 \%$ glutaraldehyde, in $0.05 \mathrm{M}$ cacodylate buffer, $\mathrm{pH} 7.4$ at $4{ }^{\circ} \mathrm{C}$ for $1 \mathrm{~h}$. After washes and dehydration in ethanol, they were embedded in LR White (London Resin). Thin sections were collected on nickel grids and treated with $0.1 \mathrm{M} \mathrm{NH} 4 \mathrm{Cl}$ in $0.1 \mathrm{M}$ PBS and then saturated with 3\% BSA and 0.1M glycine in PBS. Sections were incubated with antiGFP polyclonal antibody at room temperature for $45 \mathrm{mn}$. After several washes in PBS a gold labelled anti-rabbit IgG (GAR G10, Aurion) diluted 1/50 was applied for $30 \mathrm{mn}$. The grids were rinsed in PBS and distilled water, and finally stained with uranyl acetate. The sections were examined with Jeol 1400 (120kV) or Philips CM10 transmission electron microscopes.

\section{Acknowledgements}

The authors thank Janine Beisson and Linda Sperling for helpful comments on the manuscript. Electron microscopy has been performed at the CCME (Centre Commun de Microscopie Electronique, Université Paris Sud, Orsay, France) and the "Imagif plateforme" (CNRS, Gif sur Yvette, France). This work was supported by the CNRS and the GDR "Paramecium genomics". 


\section{References}

Allen RD. 1969. The Morphogenesis of Basal Bodies and Accessory Structures of the Cortex of the Ciliated Protozoan Tetrahymena Pyriformis. J. Cell Biol. 40:716 -733.

Allen RD. 1971. Fine structure of membraneous and microfibrillar systems in the cortex of Paramecium caudatum. J Cell Biol. 49: 1-20.

Aubusson-Fleury A, Lemullois M, De Loubresse NG, Laligné C, Cohen J, Rosnet O, Jerka-Dziadosz M, Beisson J, Koll F. 2012. The conserved centrosomal protein FOR20 is required for assembly of the transition zone and basal body docking at the cell surface. J. Cell. Sci. 125:4395-4404.

Aury J-M, Jaillon O, Duret L, Noel B, Jubin C, Porcel BM, Ségurens B, Daubin V, Anthouard V, Aiach N, Arnaiz O, Billaut A, Beisson J, Blanc I, Bouhouche K, Câmara F, Duharcourt S, Guigo R, Gogendeau D, Katinka M, Keller A-M, Kissmehl R, Klotz C, Koll F, Le Mouël A, Lepère G, Malinsky S, Nowacki M, Nowak JK, Plattner H, Poulain J, Ruiz F, Serrano V, Zagulski M, Dessen P, Bétermier M, Weissenbach J, Scarpelli C, Schächter V, Sperling L, Meyer E, Cohen J, Wincker P. 2006. Global trends of whole-genome duplications revealed by the ciliate Paramecium tetraurelia. Nature 444:171-178.

Beisson J, Sonneborn TM. 1965. Cytoplasmic Inheritance of the Organization of the Cell Cortex in Paramecium Aurelia. Proc. Natl. Acad. Sci. U.S.A. 53:275-282.

Bouchard P, Chomilier J, Ravet V, Mornon JP, Viguès B. 2001. Molecular characterization of the major membrane skeletal protein in the ciliate Tetrahymena pyriformis suggests n-plication of an early evolutionary intermediate filament protein subdomain. J. Cell. Sci. 114:101-110.

Coffe G, Le Caer JP, Lima O, Adoutte A. 1996. Purification, in vitro reassembly, and preliminary sequence analysis of epiplasmins, the major constituent of the membrane skeleton of Paramecium. Cell Motil. Cytoskeleton 34:137-151.

Collins T, Baker RL, Wilhelm JM, Olmsted JB. 1980. A cortical scaffold in the ciliate Tetrahymena. J. Ultra. Res. 70:92-103.

Damaj R, Pomel S, Bricheux G, Coffe G, Viguès B, Ravet V, Bouchard P. 2009. Crossstudy analysis of genomic data defines the ciliate multigenic epiplasmin family: strategies for functional analysis in Paramecium tetraurelia. BMC Evol. Biol. 9:125.

Dippell RV. 1968. The development of basal bodies in paramecium. Proc. Natl. Acad. Sci. 
U.S.A. 61:461-468.

Fauré-Fremiet E. 1962. Le Genre Paranassula Kahl (Ciliata cyrtophorina). Cahiers de Biologie Marine III:61-77.

Fleury A, Delgado P, Iftode F, Adoutte A. 1992. Molecular phylogeny of ciliates: What does it tell us about the evolution of the cytoskeleton and of developmental strategies? Developmental Genetics 13:247-254.

Galvani A, Sperling L. 2002. RNA interference by feeding in Paramecium. Trends Genet. 18:11-12.

Hauser K, Haynes WJ, Kung C, Plattner H, Kissmehl R. 2000. Expression of the green fluorescent protein in Paramecium tetraurelia. Eur. J. Cell Biol. 79: 144-149

Huttenlauch I, Peck RK, Plessmann U, Weber K, Stick R. 1998. Characterisation of two articulins, the major epiplasmic proteins comprising the membrane skeleton of the ciliate Pseudomicrothorax. J. Cell. Sci. 111:1909-1919.

Huttenlauch I, Peck RK, Stick R. 1998. Articulins and epiplasmins: two distinct classes of cytoskeletal proteins of the membrane skeleton in protists. J. Cell. Sci. 111:3367-3378.

Iftode F, Adoutte A, Fleury A. 1996. The surface pattern of Paramecium tetraurelia in interphase: an electron microscopic study of basal body variability, connections with associated ribbons and their epiplasmic environment. Eur. J. Protistol. 32, Supplement 1:46-57.

Iftode F, Cohen J, Ruiz F, Torres Rueda A, Chen-Shan L, Adoutte A, Beisson J. 1989. Development of surface pattern during division in Paramecium. I. Mapping of duplication and reorganisation of cortical cytoskeletal structures in the wild type. Development 105: 191-211.

Iftode F, Fleury A, Adoutte A. 1997. Development of surface pattern during division in Paramecium: III. Study of stomatogenesis in the wild type using antitubulin antibodies and confocal microscopy. European Journal of Protistology 33:145-167.

Iftode F, Fleury-Aubusson A. 2003. Structural inheritance in Paramecium: ultrastructural evidence for basal body and associated rootlets polarity transmission through binary fission. Biol. Cell 95:39-51.

Jeanmaire-Wolf R, Clérot JC, Nahon P, Iftode F, Fleury A, Adoutte A. 1993. Isolation and characterization of monoclonal antibodies to cytoskeletal and membrane proteins of the Paramecium cortex. Eur. J. Protistol. 29:311-333. 
Kaczanowska J, Iftode F, Coffe G, Prajer M, Kosciuszko H, Adoutte A. 1996. The protein kinase inhibitor 6-dimethylaminopurine does not inhibit micronuclear mitosis, but impairs the rearrangement of cytoplasmic MTOCs and execution of cytokinesis in the ciliate Paramecium during transition to interphase. Eur. J. Protistol. 32:2-17.

Keryer G, Davis FM, Rao PN, Beisson J. 1987. Protein phosphorylation and dynamics of cytoskeletal structures associated with basal bodies in Paramecium. Cell Motil. Cytoskeleton 8:44-54.

Kloetzel JA, Baroin-Tourancheau A, Miceli C, Barchetta S, Farmar J, Banerjee D, Fleury-Aubusson A. 2003. Plateins: a novel family of signal peptide-containing articulins in euplotid ciliates. J. Eukaryot. Microbiol. 50:19-33.

Kurz S, Tiedtke A. 1993. The Golgi apparatus of Tetrahymena thermophila. J. Eukaryot. Microbiol. 40:10-13.

Marrs JA, Bouck GB. 1992. The two major membrane skeletal proteins (articulins) of Euglena gracilis define a novel class of cytoskeletal proteins. J. Cell Biol. 118:14651475 .

Mitchell B, Jacobs R, Li J, Chien S, Kintner C. 2007. A positive feedback mechanism governs the polarity and motion of motile cilia. Nature 447:97-101.

Nahon P, Coffe G, Guyader H, Darmanaden-Delorme J, Jeanmaire-Wolf R, Clerot JC, Adoutte A. 1993. Identification of the epiplasmins, a new set of cortical proteins of the membrane cytoskeleton in Paramecium. J. Cell Sci. 104:975-990.

Omary MB, Ku N-O, Tao G-Z, Toilova D, Liao J. 2006. "Heads and tails” of intermediate filament phosphorylation: multiple sites and functional insights. Trends Bioch. Sci. 31: 383-394.

Peck RK. 1977. The ultrastructure of the somatic cortex of Pseudomicrothorax dubius: structure and function of the epiplasm in ciliated protozoa. J. Cell. Sci. 25:367-385.

Pomel S, Diogon M, Bouchard P, Pradel L, Ravet V, Coffe G, Viguès B. 2006. The membrane skeleton in Paramecium: Molecular characterization of a novel epiplasmin family and preliminary GFP expression results. Protist 157:61-75.

Przybos E, Tarcz S, Potekhin A, Rautian M, Prajer M. 2012. A two-locus molecular characterization of Paramecium calkinsi. Protist 163: 263-273.

Romero MR, Torres A. 1993. Cortical development associated with conjugation of Paramecium. Development 117:1099-1112.

Skouri F, Cohen J. 1997. Genetic approach to regulated exocytosis using functional complementation in Paramecium: identification of the ND7 gene required for membrane 
fusion. Mol. Biol. Cell 8:1063-1071.

Sonneborn T. 1970. Methods in Paramecium Research, p. 242-339. In Methods in Cell Physiology. Academic Press.

Sperling L, Keryer G, Ruiz F, Beisson J. 1991. Cortical morphogenesis in Paramecium: a transcellular wave of protein phosphorylation involved in ciliary rootlet disassembly. Dev. Biol. 148: 205-218.

Strüder-Kypke MC, Wright AD, Fokin SI, Lynn DH. 2000. Phylogenetic relationships of the Subclass Peniculia (Oligohymenophorea, Ciliophora) inferred from small subunit rRNA gene sequences. J. Eukaryot. Microbiol. 47:419-429.

Vladar EK, Axelrod JD. 2008. Dishevelled links basal body docking and orientation in ciliated epithelial cells. Trends Cell Biol. 18:517-520.

Vladar EK, Bayly RD, Sangoram AM, Scott MP, Axelrod JD. 2012. Microtubules enable the planar cell polarity of airway cilia. Curr. Biol. 22:2203-2212.

Wehland J, Weber K. 1987. Turnover of the carboxy-terminal tyrosine of alpha-tubulin and means of reaching elevated levels of detyrosination in living cells. J. Cell. Sci. 88:185203.

Werner ME, Mitchell BJ. 2012. Planar cell polarity: microtubules make the connection with cilia. Curr. Biol. 22:R1001-1004.

Williams NE, Honts JE, Jaeckel-Williams RF. 1987. Regional differentiation of the membrane skeleton in Tetrahymena. J. Cell. Sci. 87:457-463.

Williams NE, Honts JE, Kaczanowska J. 1990. The formation of basal body domains in the membrane skeleton of Tetrahymena. Development 109:935-942.

Williams NE, Vaudaux PE, Skriver L. 1979. Cytoskeletal proteins of the cell surface in Tetrahymena I. Identification and localization of major proteins. Exp. Cell Res. 123:311-320.

Williams NE. 2004. The epiplasm gene EPC1 influences cell shape and cortical pattern in Tetrahymena thermophila. J. Eukaryot. Microbiol. 51:201-206.

Williams NE, Honts JE, Dress VM, Nelsen EM, Frankel J. 1995. Monoclonal Antibodies Reveal Complex Structure in the Membrane Skeleton of Tetrahymena. J. Eukaryot. Microbiol. 42:422-427. 


\section{Legends to the Figures.}

Figure 1. Organisation and duplication of the epiplasm units and basal body pattern in interphase (A) and dividing (B to F) Paramecium. Projections of confocal optical sections passing through the ventral surface of cells decorated with the anti-epiplasmin CTS32 (red) and the anti-polyglutamylated tubulin ID5 (green) antibodies. Top inserts a (3.8x), b (4.1x) and $\mathrm{c}(4 \mathrm{x})$ correspond to areas indicated by squares in the corresponding images $\mathrm{A}, \mathrm{B}$ and $\mathrm{C}$. Bars are $20 \mu \mathrm{m}$.

A: In interphase cell, one (arrows in a) or two basal bodies are inserted in each epiplasm unit. A ciliated invagination, the oral apparatus $(\mathrm{OA})$ specialized in prey capture, is located in the middle of the cell. The confrontation of the antero-posterior curved rows of epiplasm units marks the anterior and the posrerior sutures (dashed lines).

B: At the beginning of division, the oral apparatus duplicates within the oral invagination (OAa and OAp); one basal body is assembled anterior to the anterior parental basal body, thus giving rise to units with two or three basal bodies (b). The process of basal body assembly starts at the cell equator, where the attenuation of the epiplasm labelling underlines the future fission line and progresses as a wave towards the two cell poles (the arrows indicate the direction of wave progression); the limits of the wave progression are underlined anteriorly and posteriorly (thin white lines).

$\mathrm{C}$ : At a later stage, the two oral invaginations (OAa and OAp) are individualized. Basal body assembly has occurred in all epiplasm units, except in the two invariant fields (cloudy white areas), which will be transmitted to the daughter cells without multiplication of their epiplasm units. Hyperduplication of basal bodies has occurred in the equatorial area (outlined by thin lines), so that up to four basal bodies are detected in elongated units (underlined in c). 
D to F: Three successive stages of cytokinesis. Thanks to the individualisation and elongation of new units, the anteroposterior rows elongate and progressively curve around the two new oral apparatuses; the fission line progressively transforms into posterior and anterior sutures of the anterior and the posterior cell respectively (arrows).

Figure 2. Phylogeny of the epiplasmins (modified from Damaj et al., 2009). The epiplasmins analysed in this study and in previous ones (Pomel et al., 2006; Damaj et al., 2009) are numbered to show their localisation in the tree.

Figure 3. Localisation of GFP-epiplasmins from the five families Atypic 4, Asymmetric 2, Symmetric 1, 3 and 5 on whole living cells by epifluorescence (A to E) and at high magnification by confocal microscopy of cells processed for immunofluorescence: A1 to G1: GFP signal, A2 to E2: corresponding double labelling with the CTS32 antibody or F2 and G2: with the ID5 antibody. Bars: $20 \mu \mathrm{m}$ in A-E and $5 \mu \mathrm{m}$ in A1-G1.

Atypic4 (At4a/Epi11): In addition to the localisation around the epiplasm units, the cytoproct, which corresponds to a portion of the posterior suture where exocytosis of food vacuoles occurs, is decorated (arrow in A). Inserts: the GFP labelling (A1) exactly encircles the epiplasm unit (A2).

Asymmetric 2 (As2a/Epi20) and Symmetric 1 (S1a/Epi41): The GFP signal is detected on the whole surface of the epiplasm units on living cells (B and C). Inserts: Symmetric 1 GFPepiplasmin exactly colocalizes with CTS32 labeling (C1 and C2). Asymmetric 2 GFPepiplasmin gave a less reproducible colocalization with the CTS32 labeling, most probably because of problems of accessibility of the CTS32 antibody to its target; on the image presented here, this GFP signal seems stronger in the center of the unit than at its periphery (B1 and B2).

Symmetric 3 (S3a/Epi30): In living cells, the macronucleus (Ma) appears strongly and uniformly fluorescent (D). The GFP is also detected at the cell surface as dots. These dots are 
located at the center of the unit (D1 and D2), and encircle the basal body (F1 and F2). A faint labelling is detected on the whole unit (F1).

Symmetric 5 (S5b/Epi51): In living cells, the GFP signal is detected both as aggregates and/or filaments everywhere in the cell and as dots at the cell surface (E). The dots, either paired or clustered by three (arrow in E1 and G1), locate in the centre of the epiplasm unit (E2); one (two) of them colocalises with the basal bodies, and the additional one locates anterior right to the posterior basal body (G2).

Figure 4. Ultrastructural localisation of the GFP asymmetric and symmetric epiplasmins by pre-embedding (As2b/Epi38; S3a/Epi30) or post-embedding (As2a/Epi20; S5a/Epi51) techniques. Bar is $500 \mathrm{~nm}$.

Immunogold labelling is detected at the level of the epiplasm layer (arrows) in exclusion to the basal bodies (arrowheads) for As2B/Epi38 and As2a/Epi20. Immunogold particles are also detected at the level of the epiplasm (arrows) and close to the basal body (arrowheads) for S3a/Epi30. Immunolabelling is exclusively observed at the basal body and the parasomal sac (star) for S5a/Epi51 (arrowheads).

Figure 5. GFP-epiplasmin localisation during cell division. All images, except $\mathrm{E}$ (epifluorescence) are projections of confocal optical sections performed at the level of the ventral side. Whole cells: merge images of cells double labelled with GFP in green and with the anti epiplasm CTS32 in red (A, B and F) or GFP and the anti-basal body ID5 in red (C, D and E). Grey rectangles correspond to the inserts:A1 to F1: GFP signal; A2 to F2: merge images. Arrowheads: fission furrow. Bars are $20 \mu \mathrm{m}$.

A and B: Dividing cells expressing Asymmetric 2 GFP epiplasmins: As2a/Epi20 (A) and As2b/Epi38 (B). The GFP signal of core epiplasmins As2a (A1) and the CTS32 labelling of the epiplasm similarly decrease in the equatorial region (A): the two labellings overlap in the 
proliferative units (A2). The GFP signal of As2b (B) disappears in the anterior part of equatorial elongating units (B1), which thus appear in red on the merge image, but not in the posterior parts (arrows in B1 and B2).

C and D: Dividing cells expressing Symmetric 3 GFP-epiplasmins (green): S3a/Epi30 (C) and S3b/Epi46 (D), double labelled with the anti-basal body ID5 (red).

$\mathrm{C}$ : Cell at an early stage of division. The fission furrow is not yet visible. One or two rings are detected in the units $(\mathrm{C} 1)$ : the ring signal is clearly associated with the posterior parental basal bodies, which appears in yellow in $\mathrm{C} 2$, but not with the anterior new one which appears in red (arrows). D: On this cell in an advanced stage of division, longitudinal rows of basal bodies corresponding to parental units are detected (underlined in D2). The GFP signal of core epiplasmins S3b disappears in the anterior part but remains at the posterior part of elongating units (arrows in D1).

E: Dividing cell expressing the symmetric 5 epiplasmin S5a/Epi51. Strings of basal bodies coming from one parental unit are still individualized (underlined by double headed arrows in E1 and E2). The GFP labelling is more intense in association with the posterior parental basal bodies than with the anterior new ones of each set (E1 and E2). In addition to the basal bodies, many aggregates of GFP signal are detected as in the interphase cell (Fig. 3). F: Dividing cell expressing the atypic 4a epiplasmin At4a/Epil1 (green). The GFP labelling is less intense in the equatorial region $(\mathrm{F})$. This slow down corresponds to duplicating units which are encircled with a thinner rim than non proliferative ones (F1).

Figure 6. Postautogamous GFP-epiplasmin expressing cells. The squares indicate the position of the inserts. Bars: $20 \mu \mathrm{m}$.

A: Symmetric 1a (S1a/Epi41): first division after autogamy: The GFP epiplasmin is detected in the core of the units of the two invariant fields, anterior and posterior (double arrows in A). Inserts: A1: GFP; A2: anti-epiplasm. Only the posterior parts of the posterior units (A1) are 
labelled after unit duplication, clearly visible after anti-epiplasm labelling (A2). The arrows point to the anterior part of a parental unit

B: Symmetric 3a (S3a/Epi30): Anterior cell after the first post-autogamous division. The GFP ring epiplasmin is detected only in association with the parental basal bodies which thus appear sparsely distributed since only approx. half of the basal bodies have a labelled ring. In the anterior field, single GFP-epiplasm rings are detected (arrows in B1).

C: Symmetric 3b (S3b/Epi46): Anterior cell from the first post-autogamous division during the second division. Core GFP-epiplasmin is detected in the units of the invariant anterior pole (double arrow), as well as in other units corresponding to the posterior part of parental units (arrows). Insert: Epiplasm rings are clearly detected (arrows in C1). In the anterior field, both one ring and one hole (arrowhead) are detected in the core of the units.

Figure 7. Ultrastructure of the basal body (A and C) and the parasomal sacs (B and D) in wild type (A and B) and S5a5/Epi51+48 depleted cells (C and D). Bars are $10 \mathrm{~nm}$. A and C: Longitudinal section through a somatic basal body. After S5a epiplasmin depletion, the epiplasm ring linking the basal body to the epiplasm detected in the control (arrow in A) is missing (arrows in C).

B and D: Transversal section through the basal bodies of the oral apparatus. This region is particularly suitable to observe the morphology of the parasomal sacs, because many of them are located between the two peniculi; in the control cell (B), they are regularly shaped and patterned. After S5a epiplasmin depletion (D), they are less regularly shaped than in control cells. Because of the absence of the epiplasm ring after S5a epiplasmin depletion (D), basal body/epiplasm connections (stars) appear less dense than in control cells (B).

Figure 8. Differential properties of the epiplasmins by reference to their phylogeny. For each epiplasmin group, three stages of the unit cycle are represented: localisation of the 
epiplasmin in one unit of the interphase cell (left square), behaviour of the epiplasmin at the beginning of the unit duplication (middle square) and at the end of the duplication (right square). Grey intensity is proportional to the observed GFP signal.

Table 1. Quantification of the gold-labelling observed by immunocytochemistry at the ultrastructural level. $\mathbf{N}$ bb : number of basal bodies used for the quantification; Labelled bb : Percentage of labelled basal bodies; Gg/lab bb: Average number of gold granules observed per labelled basal body; Localisation: percentage of basal bodies labelled at the ring, at the terminal plate, or both at the ring and the terminal plate.

Table 2. Summary of the properties of the different groups and subgroups of epiplasmins with respect to their localisation in the units of the interphase cell and their behaviour during unit duplication.

The asymmetric 2 epiplasmins are core epiplasmins. The As2a/Epi20 is an early epiplasmin, while As2b/Epi38 is a late one. The large symmetric 1 epiplasmin S1a/Epi41 is an early core epiplasmin. Unfortunately, no data is available for the symmetric $1 \mathrm{~b}$ group, because of methodological limitations. The intermediate symmetric 3 epiplasmins are both ring and core epiplasmins. The core fraction of the subgroup a, S3a/Epi30, is an early epiplasmin, while that of the subgroup b, S3b/Epi46, is a late one. In both groups, the ring epiplasmins are late ones. The atypic 4 epiplasmins are rim epiplasmins. The At4b/Epi40 of the subgroup b is detected only during division, while the At4a/Epi11 and At4a/Epi43 of the subgroup a are detected all along the cell cycle. The small symmetric 5 epiplasmin S5/Epi51 is a late basal body epiplasmin, also detected at the parasomal sac. 
Figure 1
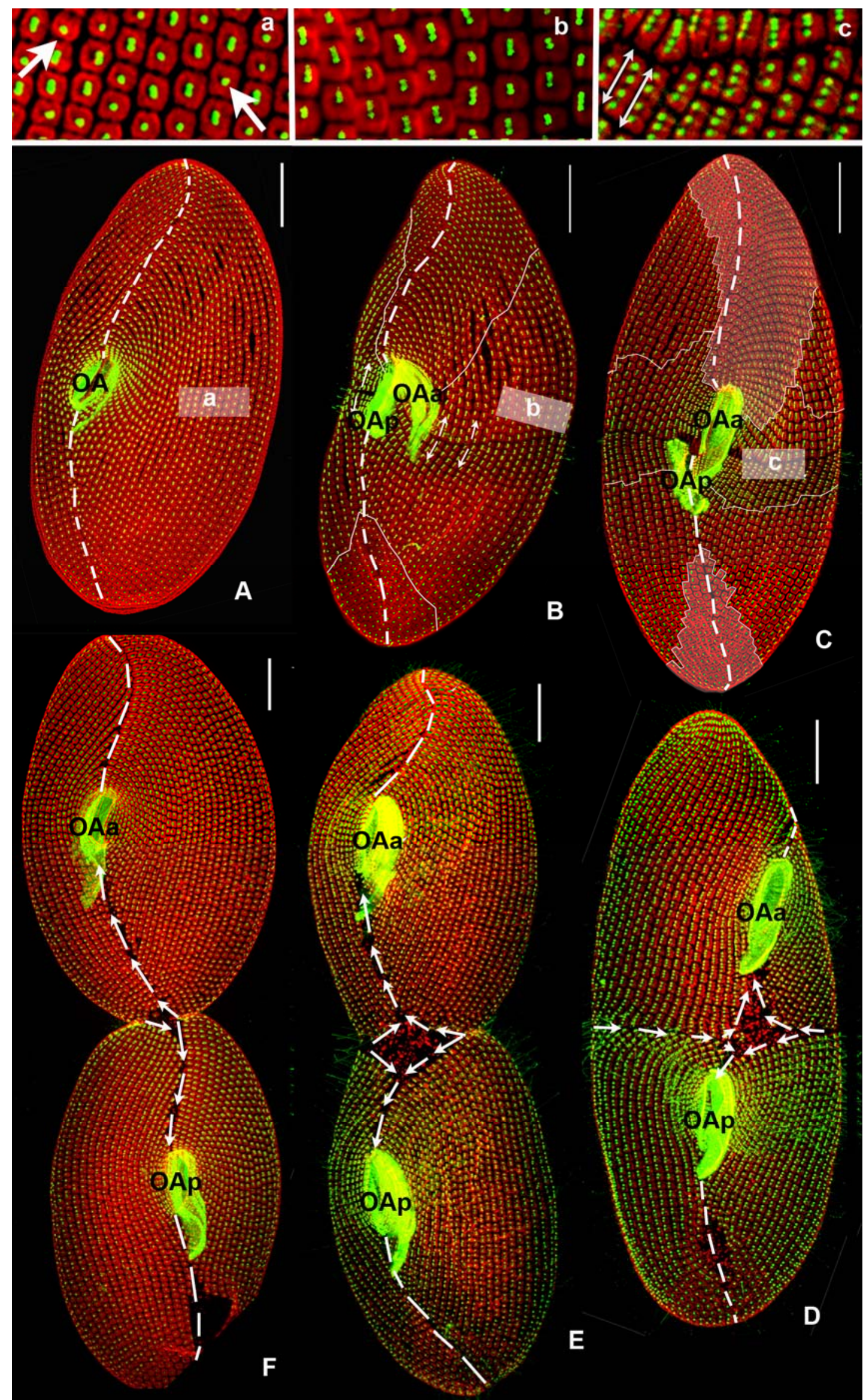
Figure 2

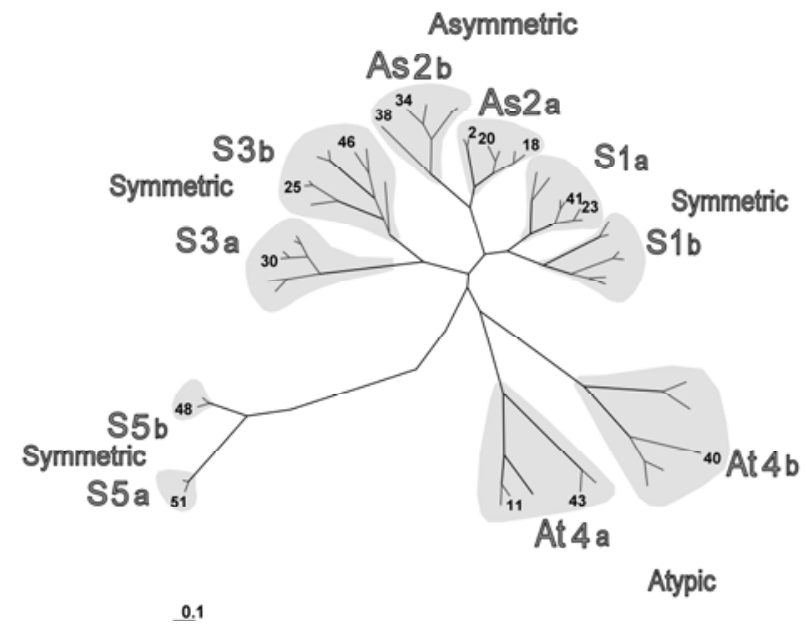


Figure 3
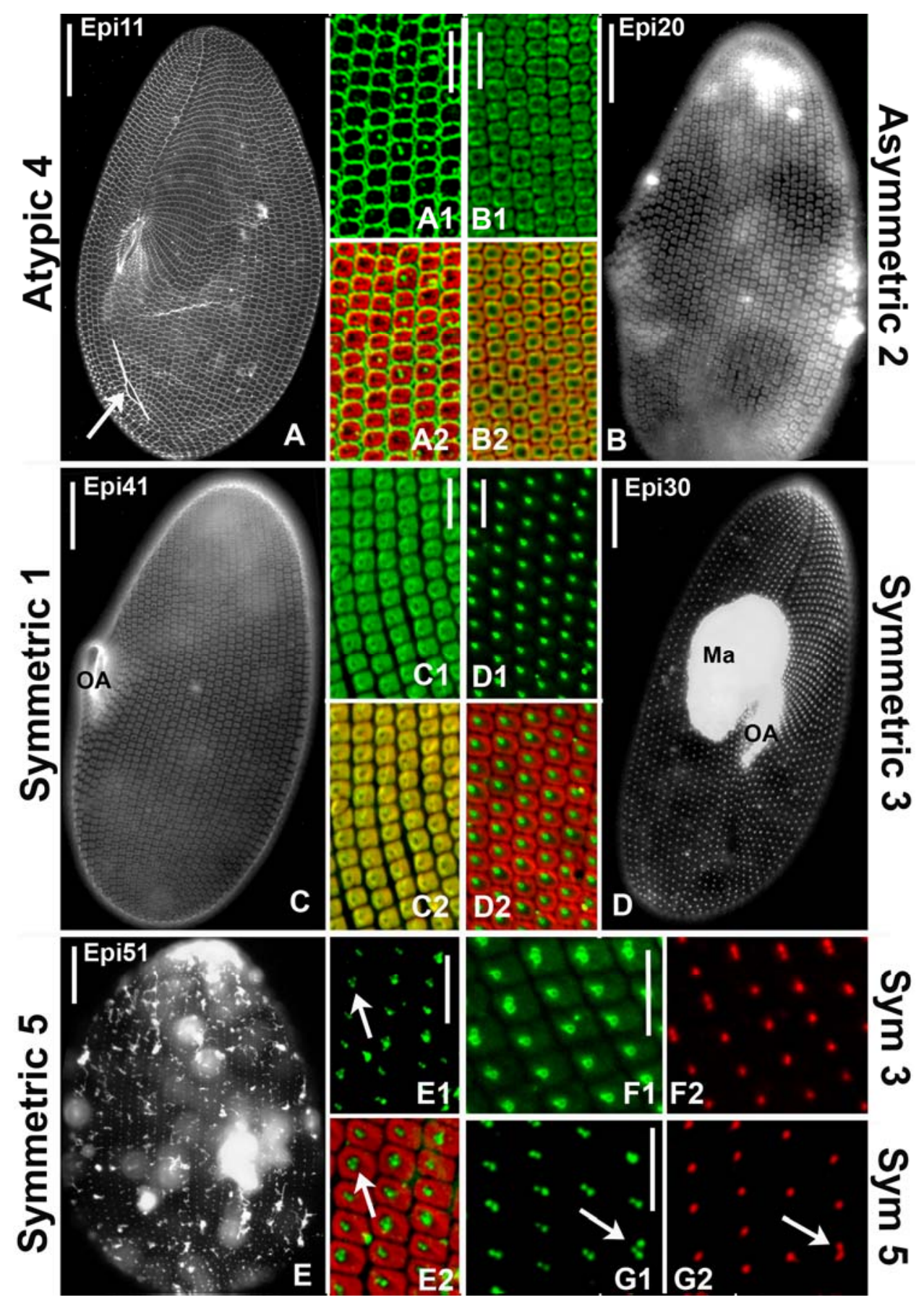
Figure 4

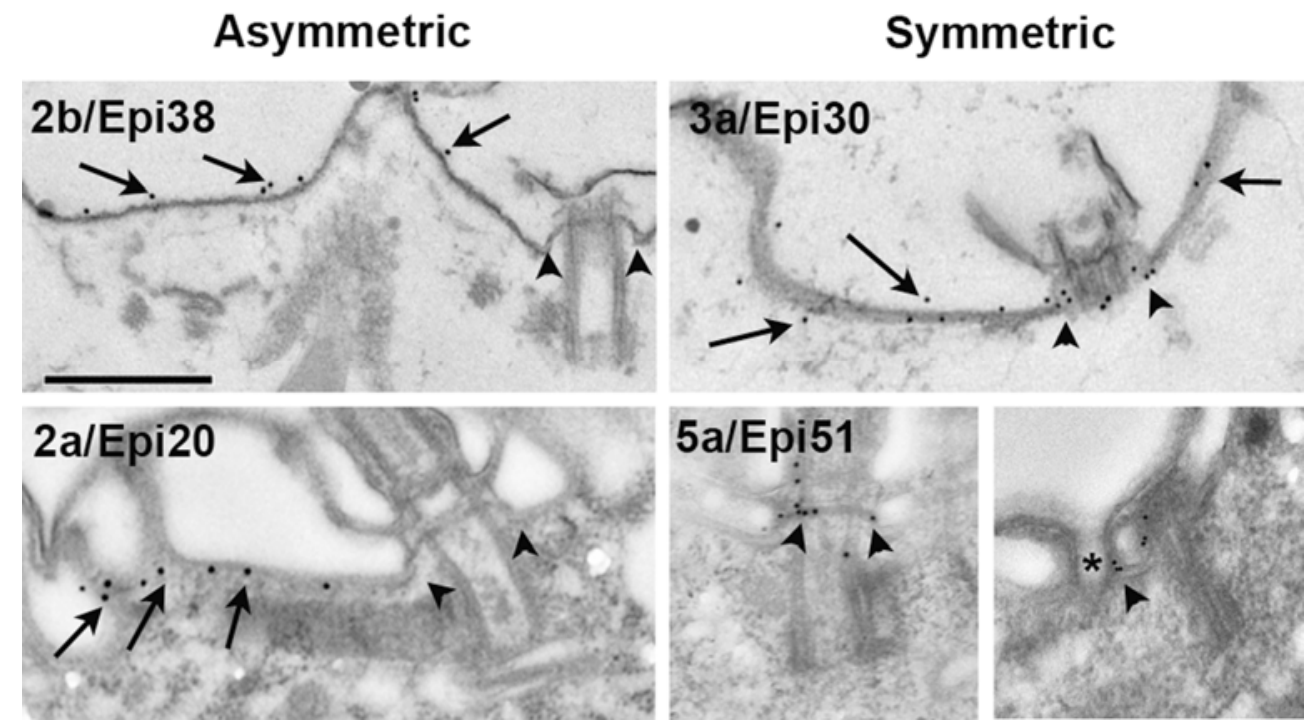


Figure 5
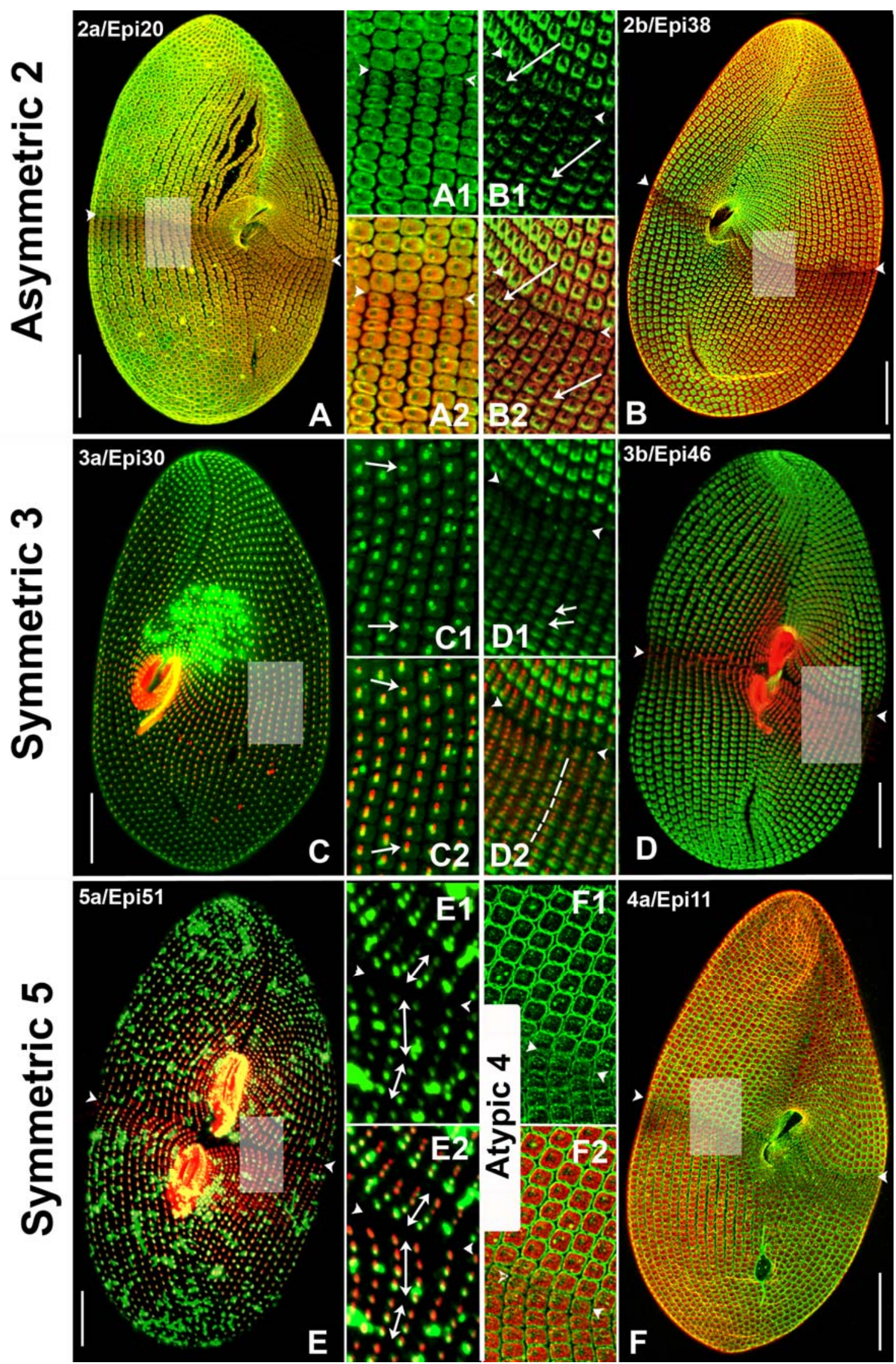
Figure 6

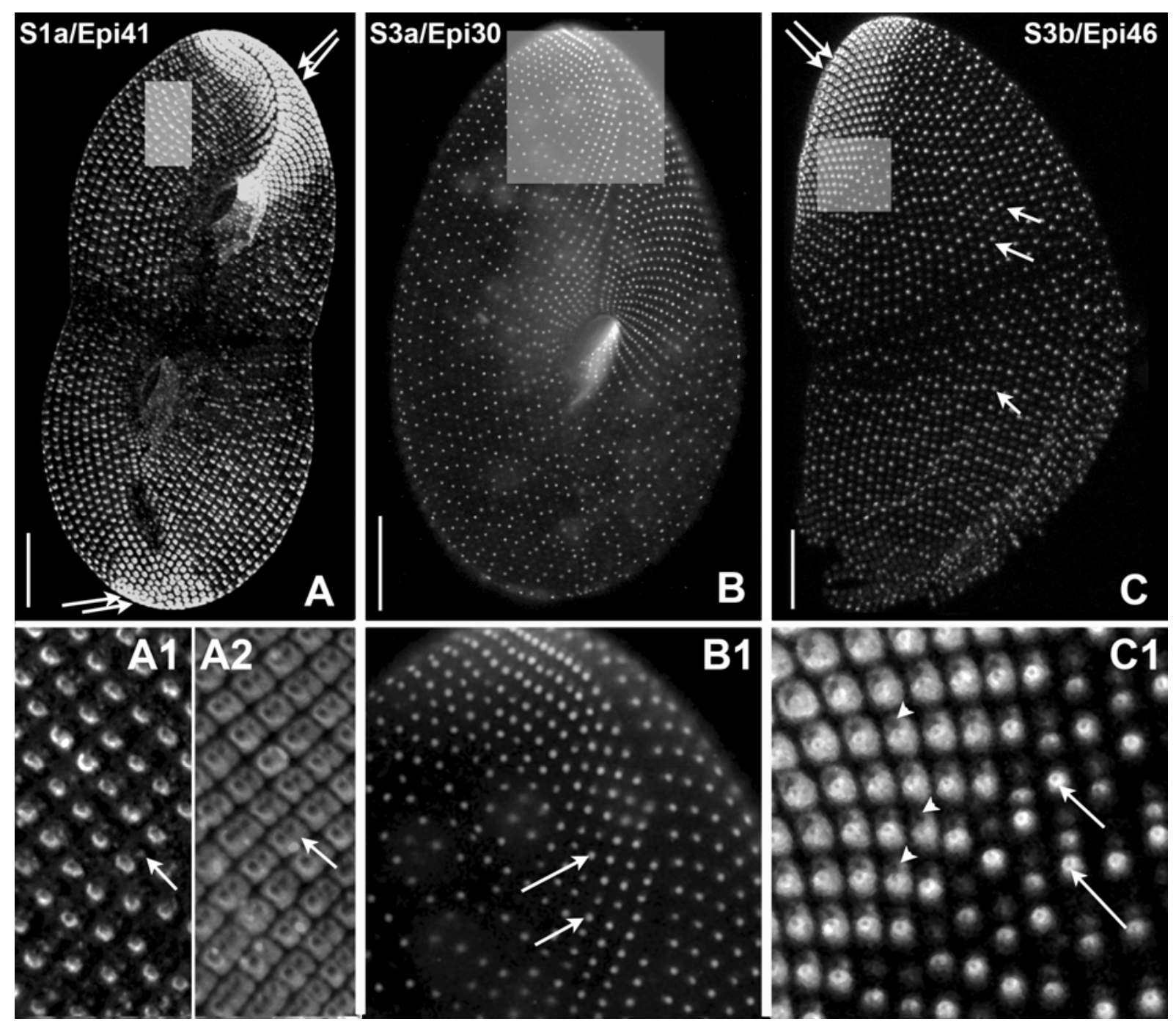


Figure 7

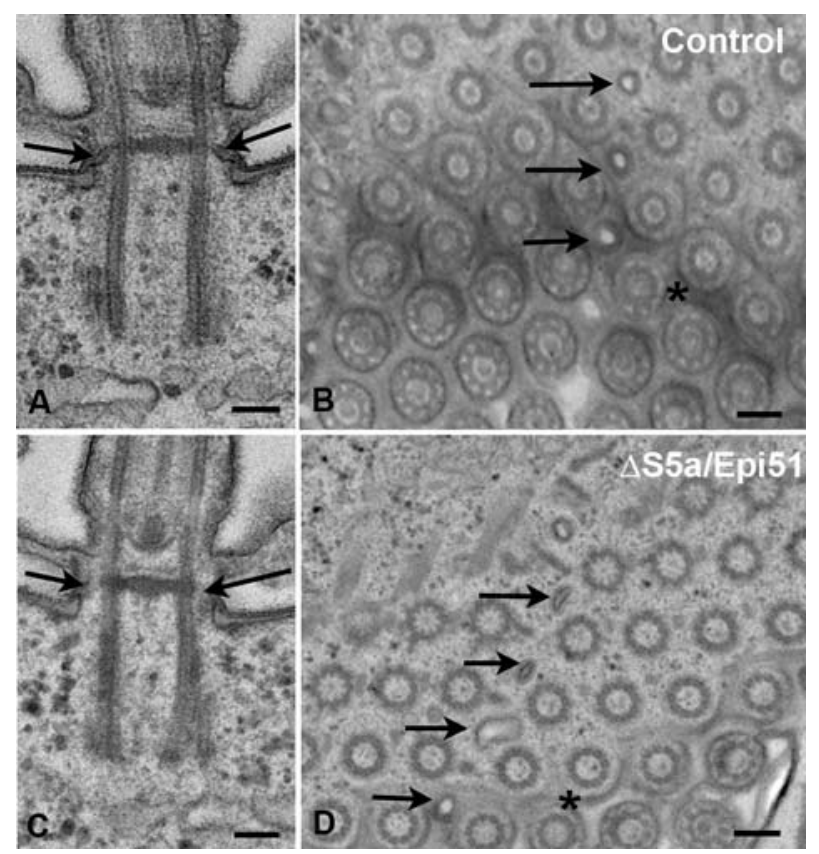

Figure 8

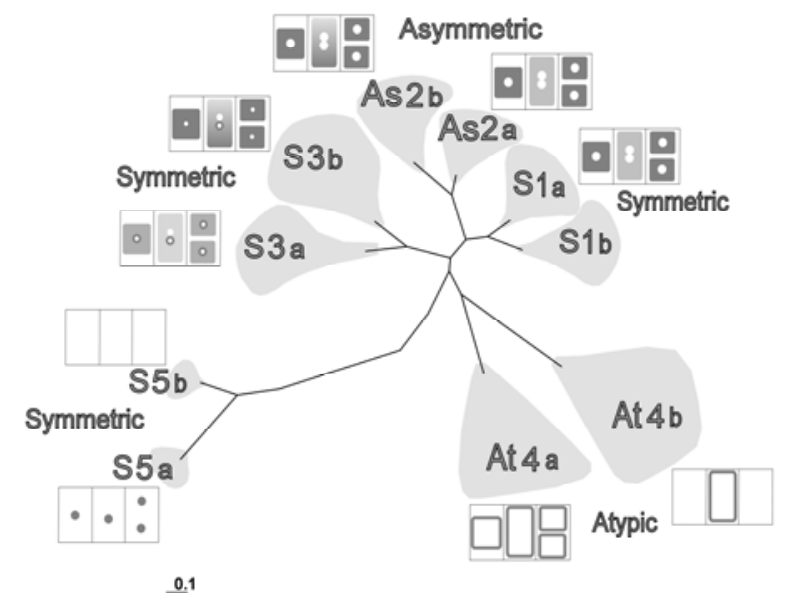


Table 1

\begin{tabular}{|c|c|c|c|c|c|c|}
\hline Epiplasmin & N bb & Labelled & Gg /lab bb & \multicolumn{3}{|c|}{ Labelling localisation } \\
\cline { 5 - 7 } & & bb & & Ring & Tp & Ring \& Tp \\
\hline As2b/Epi38 & 36 & $31 \%$ & 1,6 & $55 \%$ & $36 \%$ & $9 \%$ \\
\hline As2a/Epi20 & 97 & $35 \%$ & 1,9 & $30 \%$ & $58 \%$ & $12 \%$ \\
\hline S3a/Epi30 & 27 & $85 \%$ & 3,1 & $100 \%$ & 0 & 0 \\
\hline S5a/Epi51 & 39 & $79 \%$ & 3,6 & $40 \%$ & $20 \%$ & $40 \%$ \\
\hline
\end{tabular}

Table 2

\begin{tabular}{|c|c|c|c|c|c|c|}
\hline \multirow[t]{2}{*}{ Group } & \multirow[t]{2}{*}{ Subgroup } & \multicolumn{4}{|c|}{ Localisation } & \multirow[t]{2}{*}{ Behaviour } \\
\hline & & Rim & Core & Ring & $\mathrm{Bb}$ & \\
\hline \multirow[t]{2}{*}{ Asymmetric 2} & $\mathrm{a}$ & & $\mathrm{X}$ & & & Early \\
\hline & $\mathrm{b}$ & & $\mathrm{X}$ & & & Late \\
\hline \multirow[t]{2}{*}{ Symmetric 1} & $\mathrm{a}$ & & $\mathrm{X}$ & & & Early \\
\hline & b & \multicolumn{4}{|c|}{ not tested } & \\
\hline \multirow[t]{2}{*}{ Symmetric 3} & $\mathrm{a}$ & & $X$ & $\mathrm{X}$ & & Early/Late \\
\hline & $\mathrm{b}$ & & $\mathrm{X}$ & $\mathrm{X}$ & & Late/Late \\
\hline \multirow[t]{2}{*}{ Atypic 4} & $\mathrm{a}$ & $X$ & & & & Permanent \\
\hline & $\mathrm{b}$ & $\mathrm{X}$ & & & & Division \\
\hline \multirow[t]{2}{*}{ Symmetric 5} & $\mathrm{a}$ & & & & $\mathrm{X}$ & Late \\
\hline & b & \multicolumn{4}{|c|}{ not detected } & \\
\hline
\end{tabular}




\section{Supplementary material 1}

A: Dividing cells expressing Symmetric 1 GFP epiplasmin (S1a/Epi41) double labelled with the anti-epiplasm (red). The individualisation of the two oral apparatuses and of the fission line suggests that this cell is approx. in stage C-D of the Fig.1. Over-expression of the GFP epiplasmin interferes with longitudinal cell extension: the two oral apparatuses (arrows) are not yet separated and the unit elongation is delayed. The GFP-epiplasmin signal is less intense in the elongating units, but no antero-posterior gradient is observed (A1 and A2). Bar is 20 $\mu \mathrm{m}$.

B: Cell expressing S3a/Epi30 (green) in late division stage double labelled with the ID5 antibody (red). New units are individualized. Ring epiplasmins are associated with the parental basal bodies (arrows in B1 and B2), while only a faint ring signal is detected in association with new ones (arrowheads in B2). Bar is $20 \mu \mathrm{m}$.

C: Early dividing cell expressing S3a/Epi30, double labelled with the anti-basal body ID5 (red). In the anterior field (square in C), two rings are detected in all units (arrow in C1) but only one basal body is detected in many of them (arrow in C3), because of disassembly of the anterior basal body (arrow in C2). Bar is $20 \mu \mathrm{m}$. 
Supplementary material 1

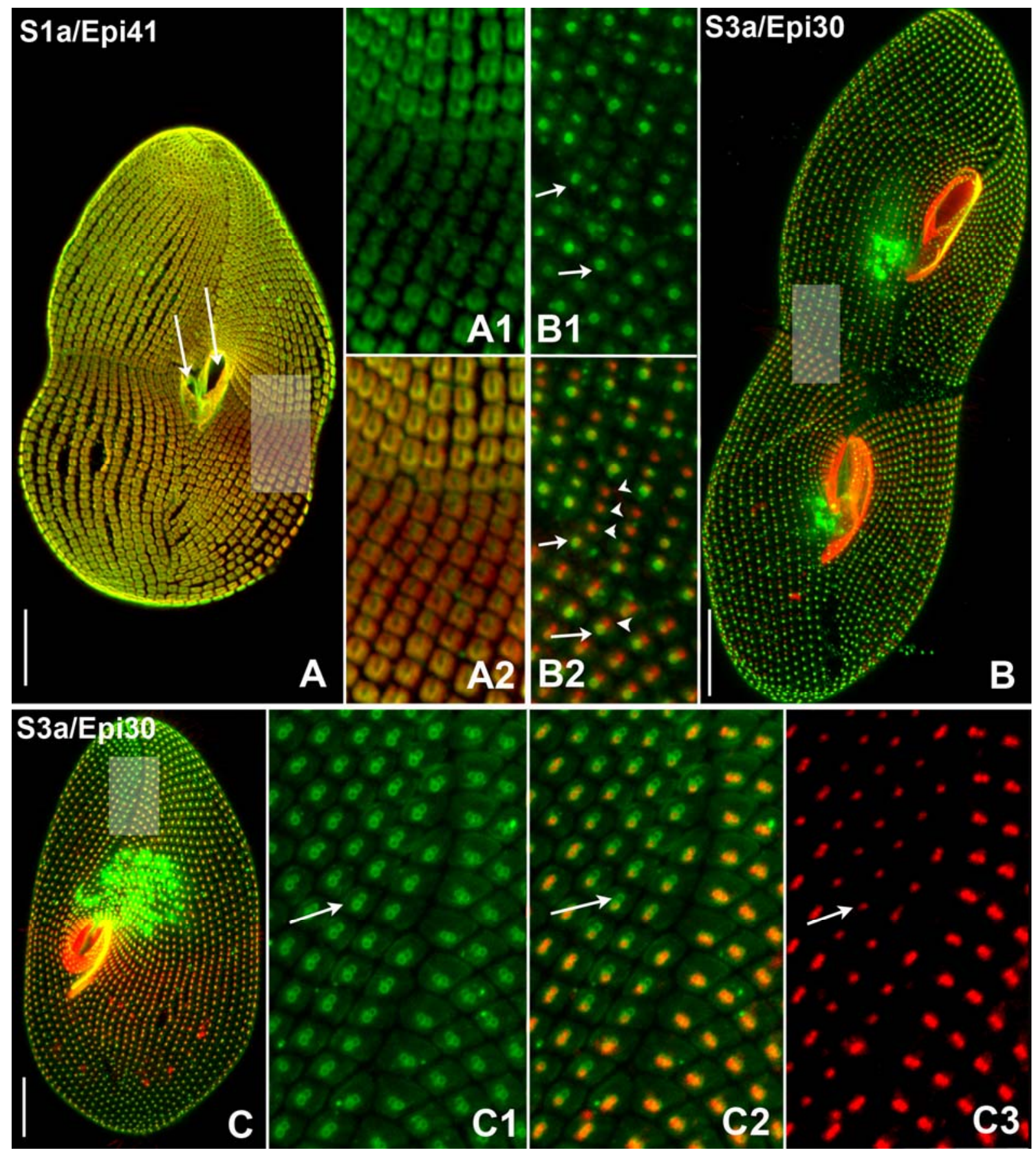


Supplementary material 2. Localisation of GFP-Atypic epiplasmins during division: A:

At4b/Epi40; B: At4a/Epi11; C: At4a/Epi43. Bars are $20 \mu \mathrm{m}$ in A and B, $5 \mu \mathrm{m}$ in C.

A and B: Cells double labelled with the anti-epiplasm (red). The GFP At4b/Epi40 (A) and the At4a/Epi11 (B) epiplasmins are detected around all the duplicating units (green). In addition, GFP material is detected at the fission line (arrows).

C: High magnification of the fission line of a dividing cell expressing the GFP-At4a/Epi43 epiplasmin (green) double labelled with the anti-basal body ID5 (red). The GFP epiplasmin accumulates at the fission line (arrow) and marks the fission line between new dividing units (arrowheads).

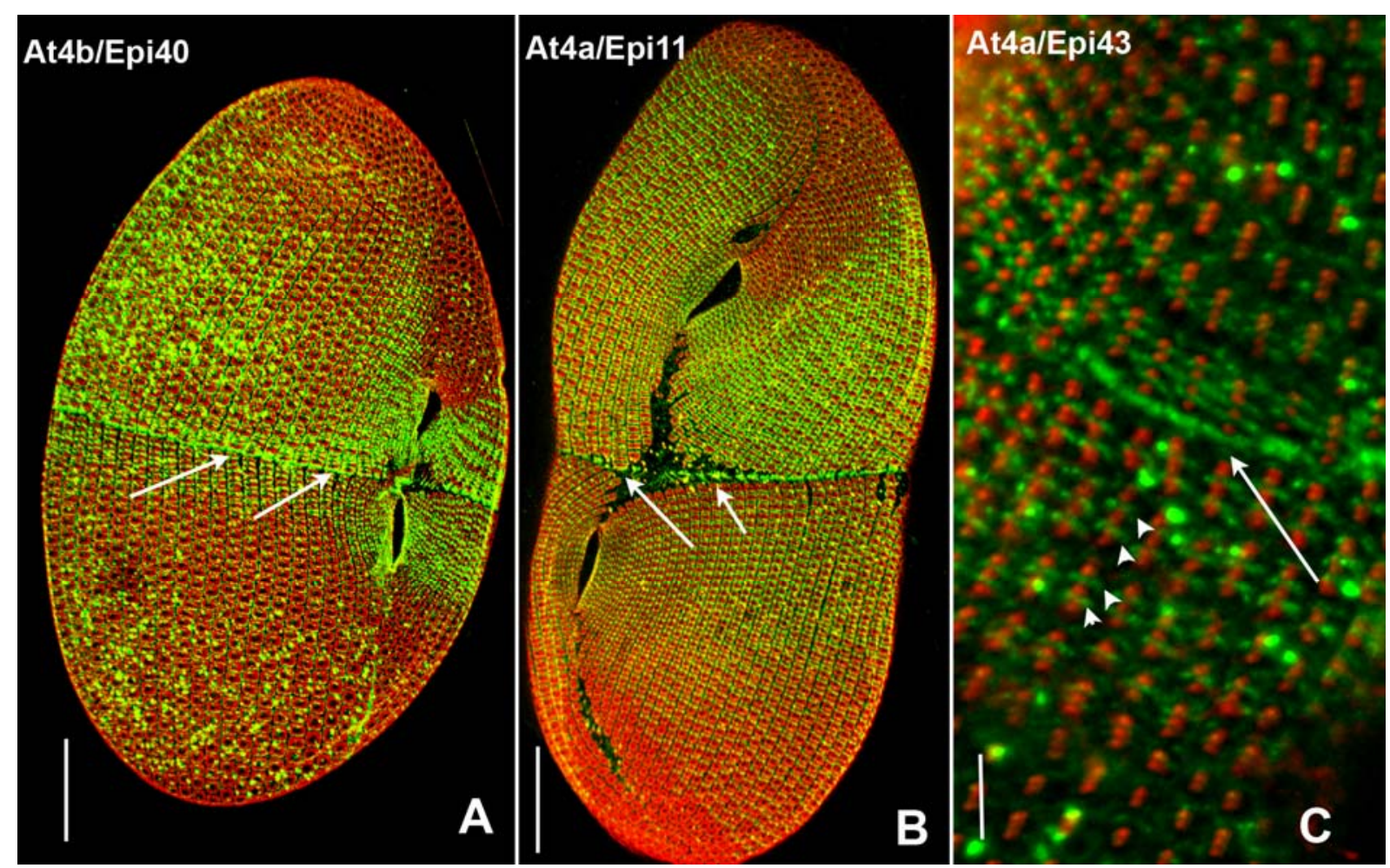




\section{Supplementary table 1}

Epiplasmins analysed in this study: phylogenetic affiliation (subgroup), biochemical characteristics (type), accession number in ParameciumDB, expression level (EST, ParameciumDB), GFP localisation and depletion phenotype of the cortical units observed at the photonic level by immunofluorescence. (1): Pomel et al., 2006; (2): Damaj et al., 2009.

\begin{tabular}{|c|c|c|c|c|c|c|}
\hline Family & Type & Protein & accession number & EST & GFP & \begin{tabular}{|l|} 
Depletion phenotype \\
\end{tabular} \\
\hline $1 a$ & Symmetric & Eni41 & GSPATP00025744001 & $60 / 164$ & core & \begin{tabular}{|l|} 
disintearation unit (?) \\
\end{tabular} \\
\hline $1 a$ & Symmetric & Epi23 & GSPATP0002397001 & $25 / 164$ & & disintegration unit \\
\hline $1 b$ & Symmetric & & & 34 & & \\
\hline $2 a$ & Asymmetric & Epi20 & GSPATP00011787001 & $19 / 231$ & core & small fused units \\
\hline $2 a$ & Asymmetric & Epi2 & GSPATP00022926001 & $32 / 231$ & core (1) & small fused units (2) \\
\hline $2 \mathrm{a}$ & Asymmetric & Epi18 & GSPATP00024301001 & $63 / 231$ & & small fused units \\
\hline $2 \mathrm{~b}$ & Asymmetric & Epi38 & GSPATP00009618001 & 6/14total & core & small fused units \\
\hline $2 b$ & Asymmetric & Epi34 & GSPATP00017440001 & 1/14total & & small fused units \\
\hline $3 a$ & Symmetric & Epi30 & GSPATP00001502001 & $1 / 21$ & ring+core & none \\
\hline $3 b$ & Symmetric & Epi46 & GSPATP00010287001 & $16 / 72$ & ring+core & not characterized \\
\hline $3 b$ & Symmetric & Epi25 & GSPATP00013326001 & $17 / 72$ & & none \\
\hline $4 \mathrm{a}$ & Atypic & Epi11 & GSPATP00032435001 & $20 / 96$ & rim & fused units \\
\hline $4 a$ & Atypic & Epi43 & GSPATP00017377001 & $15 / 96$ & rim & none \\
\hline $4 b$ & Atypic & Epi40 & GSPATP00035145001 & $4 / 13$ & $\operatorname{rim}($ div) & none \\
\hline $5 a$ & Symmetric & Epi51 & GSPATP00033927001 & $6 / 9$ & ring/bb & none \\
\hline $5 b$ & Symmetric & Epi48 & GSPATP00018713001 & $2 / 2$ & none & none \\
\hline
\end{tabular}


Supplementary table 2 (modified from Damaj et al., 2009) : number of common 23 mers between epiplasmin genes for evaluation of cross-RNA interference of analyzed genes.

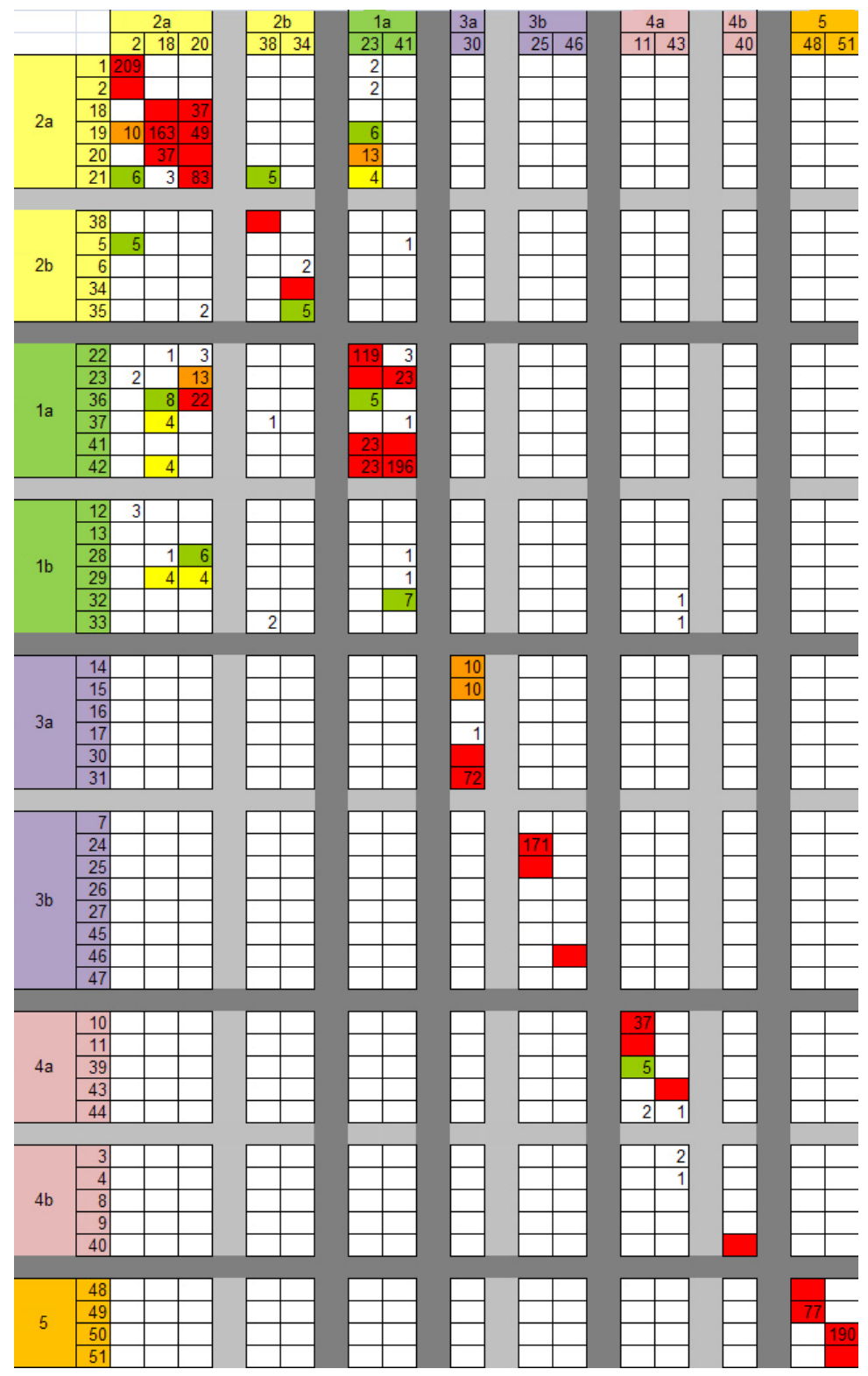

